\title{
Application of Supercritical Fluid Extraction and Chromatography to Assay Fat-Soluble Vitamins in Hydrophobic Ointment
}

\author{
Mitsuhiro Masuda, Shinichi KoIke, Mitsuichi Handa, Kazuhiko Sagara and Taku Mizutani \\ Research Center, Taisho Pharmaceutical Co., Ltd., Yoshinocho, Omiya, Saitama 330, Japan
}

\begin{abstract}
The determination of retinol palmitate and tocopherol acetate in a hydrophobic ointment by a coupled supercritical fluid extraction (SFE) and supercritical fluid chromatography (SFC) system is described. The ointment, triturated with diatomaceous earth powder, was subjected to SFE with carbon dioxide, and the extract containing fat-soluble vitamins was trapped on a trimethylsilyl silica-gel column by reducing the fluid pressure. The trapped components were analyzed on an octadecylsilyl silica-gel column by SFC using carbon dioxide containing ethanol as a mobile phase and UV absorption monitoring at $284 \mathrm{~nm}$. In this method, retinol palmitate and tocopherol acetate in preparations could be determined within ten minutes without any manual products after placing the sample into the system.
\end{abstract}

Keywords Supercritical fluid extraction, supercritical fluid chromatography, fat-soluble vitamin, retinol palmitate, tocopherol acetate

The determination of fat-soluble vitamins, retinol and tocopherol, in pharmaceutical preparations has been carried out using various techniques, such as spectrophotometry ${ }^{1,2}$, gas chromatography ${ }^{3}$ and highperformance liquid chromatography. ${ }^{4-6}$ However, these methods require manual extraction procedures. Recently, supercritical fluid extraction (SFE) and chromatography (SFC) have been studied regarding the analysis of oily components in both natural products and drugs. Especially, a coupled SFE/SFC system could simplify the analytical procedure. ${ }^{7-9}$ Many reports concerning SFE and SFC for fatty acids, fats and oils have appeared. ${ }^{10-12}$

This report describes the application of a coupled SFE/ SFC system used for the determination of fat-soluble vitamins, such as retinol palmitate and tocopherol acetate, in a hydrophobic ointment.

\section{Experimental}

\section{Chemicals}

Carbon dioxide with a purity of more than $99.99 \%$ was obtained from Kanto Sanso Ind., Co., Ltd., Tokyo. The ethanol used was of analytical grade, and obtained from Wako Pure Chemicals Ind., Ltd., Osaka. Retinol palmitate and tocopherol acetate, used as standard substances, were of raw-material grade based on preparations from Roche Ind., Ltd., Switzerland.

\section{Apparatus}

The supercritical fluid extraction and chromatografic system (SUPER-200 SYSTEM 3, JASCO Corp., Tokyo) was equipped with a multi-channel spectrophotometer
(MULTI-340, JASCO Corp., Tokyo) and a UV/VIS spectrophotometer (875-UV, JASCO Corp., Tokyo). Figures 1(a) and 1(b) show diagrams of this SFE/SFC system. The thick line indicates the part that was kept at a higher pressure by using back-pressure regulators.

During the SFE process, the pressure before the trap column was maintained higher; after the trap column the pressure became lower. The density of the carbon dioxide was thus rapidly decreased in the trap column, resulting in the deposition of extracts on the packed bed of the trap column.

Upon completion of extraction, the flow line was switched to the SFC system, and ethanol (as a modifier)
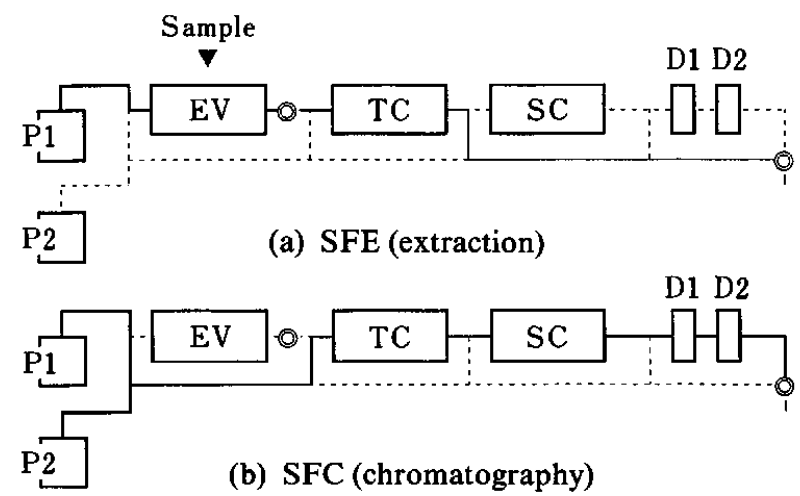

Fig. 1 Systems of SFE \& SFC. P1, pump (1) $=\mathrm{CO}_{2} ; \mathrm{P} 2$, pump (2)=ethanol; EV, extraction vessel; TC, trap column; SC, separation column; D1, spectrophotometer MULTI-340; D2, spectrophotometer $875-\mathrm{UV}$; @, back pressure regulator. 
was sent from pump (2). Supercritical carbon dioxide containing a modifier was flowed through the trap column on which the extract had been concentrated.

The extract in the trap column was then eluted and introduced into the separation column, where chromatographic separation took place. A multi-channel spectrophotometer was used to monitor real-time threedimensional chromatograms of the investigation, and a single-channel spectrophotometer was used to accurately calculate the peak areas at $284 \mathrm{~nm}$ regarding the determination.

\section{SFE conditions}

Extraction was performed at a pressure of $200 \mathrm{~kg} / \mathrm{cm}^{2}$ and a temperature of $40^{\circ} \mathrm{C}$ with supercritical carbon dioxide at a flow rate of $4.0 \mathrm{ml} / \mathrm{min}$ as liquid carbon dioxide for four minutes. Superpak SIL-C1 $(4.6 \mathrm{~mm}$ i.d. $\times 50 \mathrm{~mm}$ in length; $5 \mu \mathrm{m}$ trimethylsilyl (TMS) silicagel packing material purchased from JASCO Corp., Tokyo) was used as the trap column. As an extraction vessel, a $1 \mathrm{ml}$ vessel for the $S F E$ system was used.

\section{$S F C$ conditions}

Finepak SIL-C18 $(4.6 \mathrm{~mm}$ i.d. $\times 150 \mathrm{~mm}$ in length; $5 \mu \mathrm{m}$ ODS silica-gel packing material purchased from JASCO Corp., Tokyo) was used as the separation column. Supercritical carbon dioxide containing ethanol was used as the mobile phase ${ }^{13}$ at a flow rate of $4.0 \mathrm{ml} / \mathrm{min}$ as liquid carbon dioxide and $0.4 \mathrm{ml} / \mathrm{min}$ as liquid ethanol at a pressure of $200 \mathrm{~kg} / \mathrm{cm}^{2}$ and a temperature of $40^{\circ} \mathrm{C}$.

\section{Assay procedure}

About $1 \mathrm{~g}$ of accurately pre-weighed ointment (Table 1) and about $9 \mathrm{~g}$ of accurately pre-weighed diatomaceous earth powder were placed in a glass beaker and blended completely. About $20 \mathrm{mg}$ of this mixture (weighed accuratery) was placed in an extraction vessel. The components in the sample were extracted and chromatographed under the conditions of the coupled SFE/SFC system. The contents of retinol palmitate and tocopherol acetate were calculated from the peak areas at $284 \mathrm{~nm}$.

\section{Results and Discussion}

\section{Extraction time}

Extraction was performed at a pressure of $200 \mathrm{~kg} / \mathrm{cm}^{2}$ and a temperature of $40^{\circ} \mathrm{C}$, which are the standard

Table 1 Prescription of preparation

\begin{tabular}{ll} 
Retinol palmitate & $240000 \mathrm{I} . \mathrm{U} . / 100 \mathrm{~g}(141.1 \mathrm{mg})$ \\
Tocopherol acetate & $100 \mathrm{mg}$ \\
Ergocalciferol & $50000 \mathrm{I} . \mathrm{U}$. \\
Sulfisomidine & $5 \mathrm{~g}$ \\
Allantoin & $500 \mathrm{mg}$ \\
Zinc oxide & $5 \mathrm{~g}$ \\
\hline
\end{tabular}

conditions for SFE in this system; all of the components in this sample could be extracted in less than four minutes (Fig. 2). The time for extraction was thus set at four minutes.

\section{Effect of the pressure, temperature and modifier concentration}

The elution parameters, such as pressure, temperature and modifier concentration, were varied in order to determine the optimum condition on an octadecylsilyl (ODS)-silica gel column. At a constant temperature $\left(40^{\circ} \mathrm{C}\right)$ and modifier concentration $(10 \%$ of the flow rate of liquid carbon dioxide), as the pressure was increased the retention was decreased (Fig. 3). This tendency can be explained according to the theory that solubility variations are caused by density variations of the mobile phase. When the pressure was increased at constant temperature, the density of the fluid was increased, and

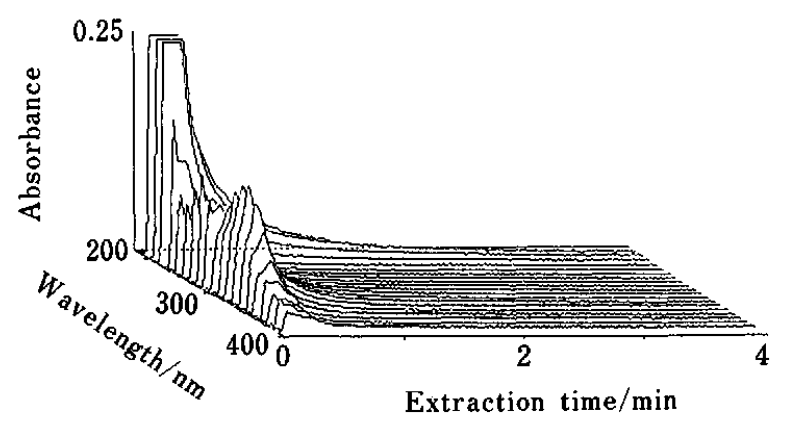

Fig. 2 Extraction curve of components in hydrophobic ointment on SFE monitoring after the extraction vessel.

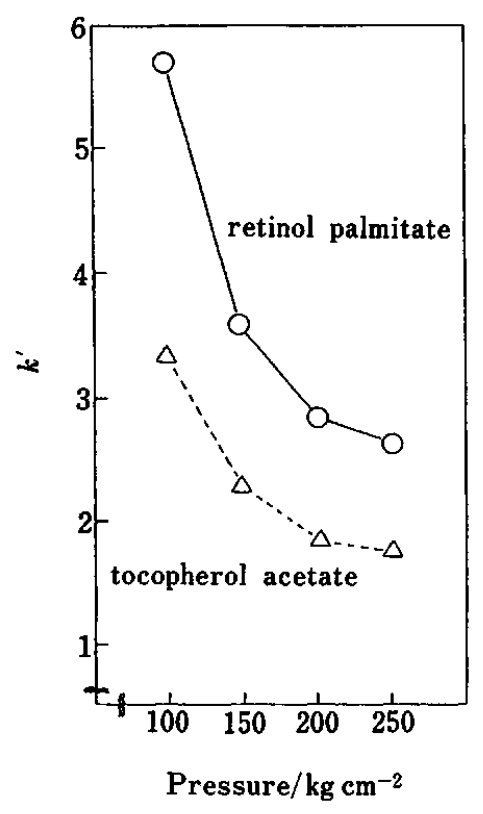

Fig. 3 Capacity ratios $\left(k^{\prime}\right)$ of retinol palmitate and tocopherol acetate as a function of the pressure on SFC. Temperature, $40^{\circ} \mathrm{C}$; modifier concentration, $10 \%$; flow rate of $\mathrm{CO}_{2}, 4.0 \mathrm{ml} / \mathrm{min}$. 
the retention was decreased. Good separation of these components was then obtained at a lower pressure. The pressure at the time of the determination was set at $200 \mathrm{~kg} / \mathrm{cm}^{2}$ with regard to the time required and the peak shapes. Under these conditions, the resolution (Rs) was 4.2.

At a constant pressure $\left(200 \mathrm{~kg} / \mathrm{cm}^{2}\right)$ and modifier concentration $(10 \%)$, though the temperature was increased, the retention did not vary much. This fact suggests that the density of the supercritical fluid depends on the absolute temperature, and that the variation of the temperature in this experiment was too small to have any effect on the density.

At a constant temperature $\left(40^{\circ} \mathrm{C}\right)$ and pressure $\left(200 \mathrm{~kg} / \mathrm{cm}^{2}\right)$, as the modifier concentration increased the retention decreasd (Fig. 4); good separation of these components was obtained at lower concentration. This tendency can be explained based on the idea that the retention depends on the polarity of the mobile phase with

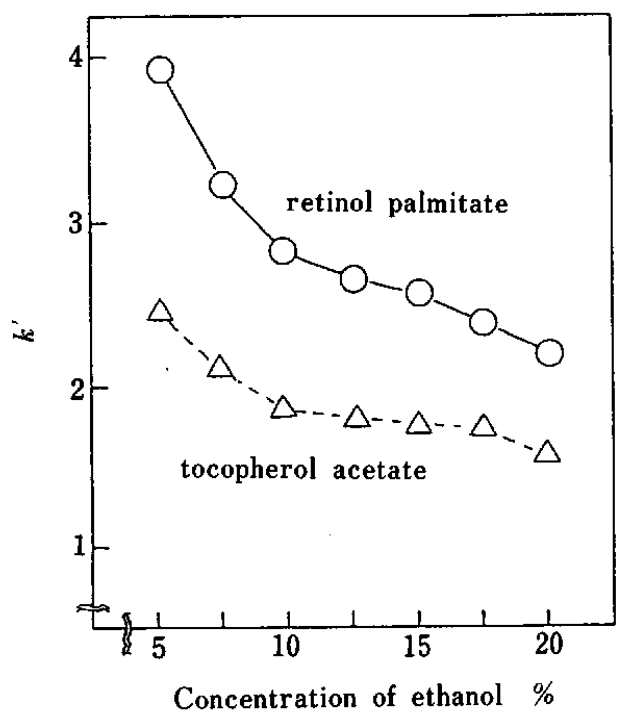

Fig. 4 Capacity ratios $\left(k^{\prime}\right)$ of retinol palmitate and tocopherol acetate as a function of the modifier concentration on SFC. Temperature, $40^{\circ} \mathrm{C}$; pressure, $200 \mathrm{~kg} / \mathrm{cm}^{2}$; flow rate of $\mathrm{CO}_{2}, 4.0 \mathrm{ml} / \mathrm{min}$.

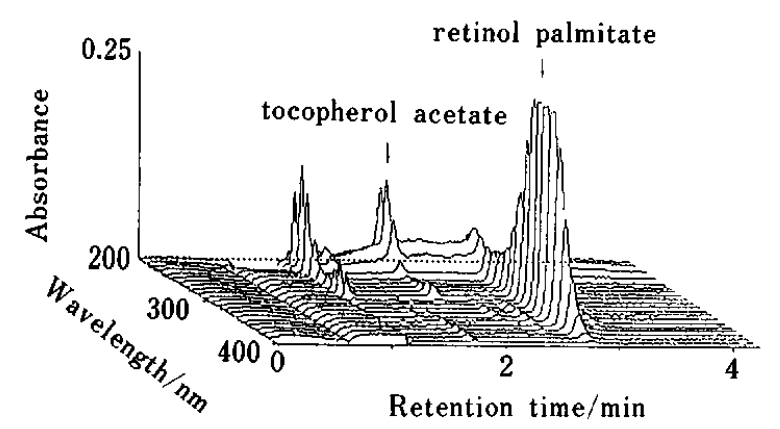

Fig. 5 Three-dimensional chromatogram of retinol palmitate and tocopherol acetate in sample mixture. chromatography. The modifier concentration for the determination was thus set at $10 \%$.

\section{Wavelength}

From a three-dimensional chromatogram of the sample, the distortion of base line was observed at a shorter wavelength (Fig. 5). The wavelength at the time of the determination was thus set at $284 \mathrm{~nm}$.

\section{Calibration curves}

Calibration curves for retinol palmitate and tocopherol acetate were obtained from $0.5-2.5 \mu \mathrm{g}$, respectively. The regression equations were as follows: $Y=$ $197625 X-6213(r=0.999)$ for retinol palmitate and $Y=21713 X-1227 \quad(r=0.997)$ for tocopherol acetate, respectively, where $Y$ is the peak area and $X$ is the amount of each compound $(\mu \mathrm{g})$.

\section{Recovery test}

Known amounts of retinol palmitate and tocopherol acetate were added to a sample mixture containing a preparation which lacked these two components; the amount of each component was determined using the present coupled SFE/SFC system. The recovery rates for retinol palmitate and tocopherol acetate were 102.0 and $101.5 \%$, respectively. Based on this result, our present method can be satisfactorily used for the quantitative determination of retinol palmitate and tocopherol acetate in this preparation.

\section{Results of determination}

The analytical results for the preparation were (a) standard solution



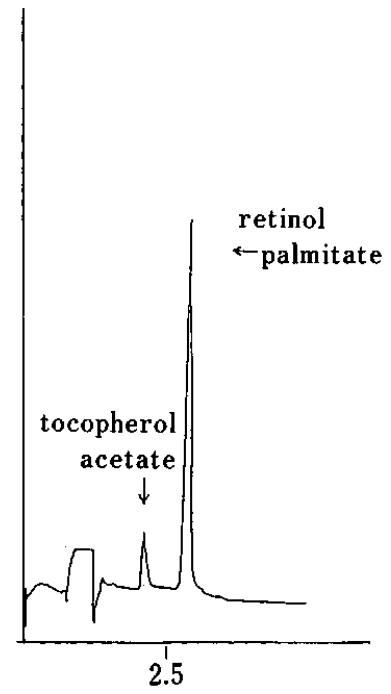

(b) sample mixture $(20 \mathrm{mg})$

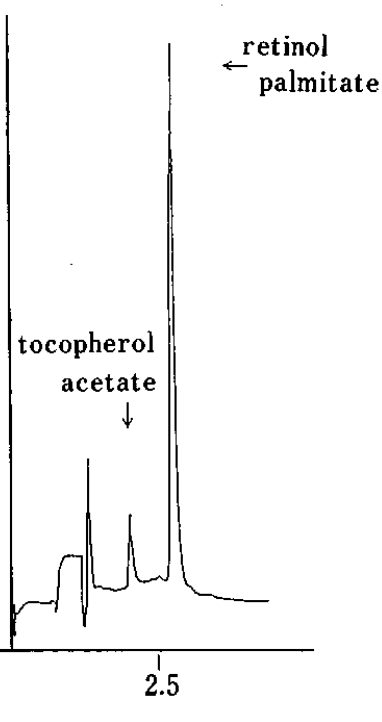

Fig. 6 Chromatogram of retinol palmitate and tocopherol acetate at $284 \mathrm{~nm}$ on SFC. Temperature, $40^{\circ} \mathrm{C}$; pressure, $200 \mathrm{~kg} / \mathrm{cm}^{2}$; modifier concentration, $10 \%$; flow rate of $\mathrm{CO}_{2}$, $4.0 \mathrm{ml} / \mathrm{min}$. 
$139.1 \mathrm{mg} / 100 \mathrm{~g}$ of retinol palmitate and $103.2 \mathrm{mg} / 100 \mathrm{~g}$ of tocopherol acetate; the chromatograms are shown in Fig. 6.

From these results it was proved that the present method is applicable to the determination of these two components in this preparation within $10 \mathrm{~min}$ without any manual products after placing the sample in the extraction vessel. The accuracy of this method was equivalent to that of the conventional method by solvent extraction and HPLC.

This study suggests that a directly coupled SFE/SFC system should be a valuable method for the quantitative analysis of preparations, including the fat-soluble components.

This work was reported in part at the 112nd Annual Meeting of the Pharmaceutical Society of Japan, Fukuoka, March, 1992, “Abstracts Papers”, 4, 129 (1992).

\section{References}

1. O. A. Bessey, O. H. Lowry, M. J. Brock and J. A. Lopez,
J. Biol. Chem., 166, 177 (1946).

2. G. Katsui and Y. Matsuoka, Vitamin, 8, 348 (1955).

3. The United States Pharmacopoeia XXII (1990).

4. S. A. Barnett and L. W. Frick, Anal. Chem., 51, 641 (1979).

5. S. K. Reeder and G. L. Park, J. Assoc. Off. Anal. Chem., 58, 595 (1975).

6. I. Stewart, J. Agric. Food Chem., 25, 1132 (1977).

7. K. Suto, K. Sagara and T. Mizutani, Shoyakugaku Zasshi, 45, 29 (1991).

8. K. Sugiyama, T. Shiokawa and T. Moriya, J. Chromatogr., 515, 555 (1990).

9. M. Saito and Y. Yamauchi, J. Chromatogr. Sci., 27, 79 (1989).

10. V. J. Krukonis, J. Am. Oil Chem. Soc., 66, 818 (1989).

11. M. Saito and Y. Yamauchi $J$. Chromatogr., 505, 237 (1990).

12. B. W. Wright, H. R. Udseth and R. D. Smith, J. Chromatogr., 314, 253 (1990).

13. K. Ogaki, R. Nishikawa, T. Furuichi and T. Katayama, Kagakukougakuronbunshu, 14, 342 (1988).

(Received August 10, 1992) (Accepted November 26, 1992) 